\title{
ALUNOS PÚBLICO-ALVO DA EDUCAÇÃO ESPECIAL NAS ESCOLAS DO CAMPO DA REGIÃO CENTRO-OESTE: ANÁLISE DE INDICADORES DE MATRÍCULAS
}

\author{
ALUMNOS PÚBLICO OBJETIVO DE LA EDUCACIÓN ESPECIAL EN LAS \\ ESCUELAS RURALES DE LA REGIÓN CENTRO-OESTE: ANÁLISIS DE \\ INDICADORES DE MATRÍCULAS
}

\section{SPECIAL EDUCATION TARGET PUBLIC STUDENTS IN MIDWESTERN RURAL SCHOOLS: ANALYSIS OF ENROLLMENT INDICATORS}

\author{
Washington Cesar Shoiti NOZU ${ }^{1}$ \\ Aline Maira da SILVA ${ }^{2}$ \\ Bruno Carvalho dos SANTOS ${ }^{3}$
}

RESUMO: Situando-se no conjunto das problematizações que emergem da interface entre Educação Especial e Educação do Campo, o presente artigo objetiva analisar o acesso de alunos Público-Alvo da Educação Especial (PAEE) nas escolas do campo da região Centro-Oeste, a partir de dados censitários oficiais de matrícula, no período de 2007 a 2017. Trata-se de uma pesquisa documental, tendo como fonte os microdados estatísticos do Censo Escolar, que foram lidos e tratados por meio do software IBM SPSS Statistics. Os resultados evidenciam a presença de alunos PAEE em escolas do campo do cenário investigado, cujas matrículas estão concentradas no Ensino Fundamental. Dentre o PAEE, os estudantes com deficiência intelectual apresentam maior índice de matrículas na região Centro-Oeste. Conclui-se que o aprofundamento da temática requer estudos empíricos em diversos contextos.

PALAVRAS-CHAVE: Dados censitários. Educação especial. Educação do campo.

RESUMEN: Al situarse en el conjunto de las problematizaciones que emergen de la interfaz entre Educación Especial y Educación Rural, el presente artículo objetiva analizar el acceso de alumnos Público Objetivo de la Educación Especial (PAEE) en las escuelas rurales de la región Centro-Oeste, a partir de datos censales oficiales de matrícula, en el período de 2007 a 2017. Se trata de una investigación documental, que ha tenido como fuente los microdatos estadísticos del Censo Escolar que han sido leídos y tratados a través del software IBM SPSS Statistics. Los resultados evidencian la presencia de alumnos PAEE en escuelas rurales del escenario investigado, cuyas

\footnotetext{
${ }^{1}$ Universidade Federal da Grande Dourados (UFGD), Dourados - MS - Brasil. Docente do Programa de Pós-Graduação em Fronteiras e Direitos Humano. Doutor em Educação. ORCID <https://orcid.org/00000003-1942-0390>. E-mail: wcsn1984@yahoo.com.br

${ }^{2}$ Universidade Federal da Grande Dourados (UFGD), Dourados - MS - Brasil. Docente do Programa de Pós-Graduação em Educação. Doutora em Educação Especial. ORCID <https://orcid.org/0000-00028439-0477>. E-mail: alinemaira@yahoo.com.br

${ }^{3}$ Universidade Federal da Grande Dourados (UFGD), Dourados - MS - Brasil. Acadêmico do Curso de Psicologia. Bolsista de Iniciação Científica. ORCID <https://orcid.org/0000-0002-5579-6945>. E-mail: bruno_carvalho1@hotmail.com
} 
matrículas están concentradas en la Enseñanza Fundamental. Entre el PAEE, los estudiantes con discapacidad intelectual presentan el índice más grande de matrículas en la región Centro-Oeste. Se concluye que la profundización de la temática requiere estudios empíricos en diversos contextos.

PALABRAS CLAVE: Datos censitarios. Educación especial. Educación rural.

ABSTRACT: Based on the problematizations set that emerge from the interface between Special Education and Rural Education, this paper aims to analyze Special Education Target Public (PAEE) students access in Midwestern rural schools, based on enrollment official census data, from 2007 to 2017. This is a documentary research, having statistical microdata of the School Census as source, which were read and processed through the IBM SPSS Statistics software. The results evidence the presence of PAEE students in rural schools of the scenario investigated, whose enrollments are concentrated in Elementary School. Among the PAEE, students with intellectual disabilities have a higher enrollment rate in the Midwest. It is concluded that the deepening of the thematic requires empirical studies in diverse contexts.

KEYWORDS: Census Data. Special Education. Rural Education.

\section{Introdução}

Há uma década, a Política Nacional de Educação Especial na Perspectiva da Educação Inclusiva foi publicada com o intuito de garantir o acesso, a participação e a aprendizagem de alunos com deficiência, transtornos globais do desenvolvimento e altas habilidades/superdotação, definidos como Público-Alvo da Educação Especial (PAEE), nas classes comuns do ensino regular (BRASIL, 2008a).

Nessa proposta, a atuação da Educação Especial deve perpassar todos os níveis, etapas e modalidades de ensino, de forma complementar e suplementar à escolarização do PAEE (BRASIL, 2008a). Para tanto, as principais ações do governo federal têm induzido, financeiramente, a realização de Atendimento Educacional Especializado (AEE), no contraturno da escolarização na classe comum, em Salas de Recursos Multifuncionais (SRMs).

Dentre as transversalidades da Educação Especial, a política em vigência prevê que a mesma seja ofertada na Educação do Campo, assegurando que "os recursos, serviços e atendimento educacional especializado estejam presentes nos projetos pedagógicos construídos com base nas diferenças socioculturais" (BRASIL, 2008a) das populações do campo, a saber: "agricultores familiares, extrativistas, pescadores 
artesanais, ribeirinhos, assentados e acampados da Reforma Agrária, quilombolas, caiçaras, indígenas e outros" (BRASIL, 2008b).

Entretanto, a partir de levantamentos estatísticos, "sabe-se que a maioria de pessoas com deficiência no país vive sem acesso à educação, sendo que com as precárias condições de vida no campo esse acesso é ainda menor" (CAIADO; MELETTI, 2011, p. 102). Este dado parece ecoar a dupla exclusão histórica, denunciada por Soares (2011, p. 59) nas seguintes palavras: "se o camponês ainda não é visto como sujeito de direitos, que dirá dos camponeses com deficiência!". Trata-se de um mecanismo de marginalização, baseado em marcações biológicas e de origem, que funciona para silenciar e invisibilizar os sujeitos com deficiência oriundos do campo, alijando-os, muitas vezes, do acesso aos direitos fundamentais, dentre os quais se destaca a educação.

Em face desse quadro, torna-se oportuna uma análise do acesso dos estudantes PAEE em escolas do campo, mormente em razão dos 10 anos da Política Nacional de Educação Especial na Perspectiva da Educação Inclusiva e dos discursos que têm circulado sobre a sua atualização/reformulação.

Nessa empreitada, Stephen J. Ball, em entrevista dada a Mainardes e Marcondes (2009), orienta que a análise de uma política pública deve estar atenta a duas dimensões básicas: espaço e tempo. Isso porque "podemos refletir a respeito das políticas em termos de espaços e em termos de tempo, de trajetórias políticas, movimentos de políticas através do tempo e de uma variedade de espaços" (MAINARDES; MARCONDES, 2009, p. 307).

Em vista disso, o presente analisa os indicadores educacionais de matrícula de alunos PAEE nas escolas do campo da região Centro-Oeste, no período compreendido entre 2007 e 2017.

A delimitação espacial ancora-se na justificativa de que, embora algumas investigações já abordem, de forma consistente, indicadores oficiais de matrícula de estudantes PAEE em escolas do campo, as ênfases situam-se no âmbito nacional e/ou em estados das regiões Sudeste e Sul. Assim, acompanhando o posicionamento de Jesus e Anjos (2012, p. 1821), é preciso "ampliarmos essa rede inicial para outras regiões e outros Estados brasileiros, fazendo abrir espaços de discussão, criando zonas de inteligibilidade e de diálogo entre a educação especial e a educação do campo".

Por sua vez, no que diz respeito à dimensão do tempo, buscou-se acompanhar a movimentação desses indicadores no decurso de uma década, tendo como marco inicial 
o ano de 2007, que antecede a publicação da Política Nacional de Educação Especial na Perspectiva da Educação Inclusiva, e final o ano de 2017, que compreende os dados censitários disponíveis mais atuais.

\section{Método}

Para alcançar o objetivo proposto foi realizada pesquisa documental, caracterizada pelo uso de fontes primárias para coletar e reunir informações acerca de um objeto de estudo (MARCONI; LAKATOS, 2007). Como fonte de dados, foram utilizados os microdados estatísticos do Censo Escolar, disponibilizado pelo Instituto Nacional de Estudos e Pesquisas Educacionais Anísio Teixeira (INEP).

O Censo Escolar é um documento que apresenta importantes informações sobre a realidade educacional brasileira, oportunizando dados gerais desde os sistemas de ensino e das unidades escolares até aspectos específicos acerca dos docentes e discentes. Trata-se de um documento de mensuração quantitativa que, mesmo com limitações, é considerado de uso imprescindível para a formulação de políticas públicas educacionais voltadas para as pessoas com deficiência (MELETTI; BUENO, 2011).

Nessa direção, o recorte desta pesquisa atém-se aos indicadores educacionais de matrícula de alunos PAEE em escolas do campo da região Centro-Oeste, composta pelos estados de Goiás, Mato Grosso e Mato Grosso do Sul e pelo Distrito Federal, entre os anos de 2007 a 2017, a partir dos microdados do Censo da Educação Básica.

Os microdados, em seu estado original, se encontram compactados e se constituem "no menor nível de desagregação de dados recolhidos por pesquisas, avaliações e exames realizados" (INEP, 2018, [n.p.]). Assim, para realizar a leitura dos microdados foi necessário o uso da versão 20 do Software Package of the Social Sciences (IBM-SPSS). Os seguintes passos foram adotados para levantamento e sistematização das informações:

1) localização do documento contendo os dados da região Centro-Oeste, seguindo as orientações propostas pelo arquivo LEIA-ME, disponibilizado pelo INEP. Após a localização, foram selecionados para análise apenas os dados referentes às escolas do campo.

2) após obter os dados quantitativos sobre os alunos matriculados em escolas do campo na região Centro-Oeste, foram localizadas as informações referentes aos alunos PAEE matriculados em tais escolas. 
3) finalmente, entre os dados localizados, foram identificadas as informações correspondentes a cada estado da região em questão. Dessa forma, em cada estado da região Centro-Oeste, levantou-se dados sobre o número de matrículas de alunos PAEE em escolas regulares utilizando como variável as dependências administrativas, as etapas de ensino e também as necessidades específicas apresentadas pelos alunos que compõem o PAEE.

\section{Resultados}

A partir da análise dos dados localizados, foi possível sistematizar quatro grupos de informações: a) número de matrículas de alunos PAEE em escolas do campo nos estados da região Centro-Oeste; b) número de alunos PAEE matriculados em escolas do campo por dependência administrativa; c) número de matrículas de alunos PAEE em escolas do campo por etapa de ensino; d) número de matrículas de alunos PAEE em escolas do campo por necessidade específica.

a) Número de matrículas de alunos PAEE em escolas do campo nos estados da região Centro-Oeste

Conforme pode ser observado na Figura 1, o número de matrículas de alunos PAEE nas escolas do campo nos estados da região Centro-Oeste cresceu entre os anos de 2007 e 2017. Esses dados coadunam com o aumento de matrículas de alunos PAEE em escolas comuns de Educação Básica no âmbito nacional, como evidenciado em alguns estudos (GONÇALVES, 2014; MELETTI; RIBEIRO, 2014).

Figura 1 - Evolução das matrículas de alunos PAEE em classes regulares nas escolas do campo da região Centro-Oeste

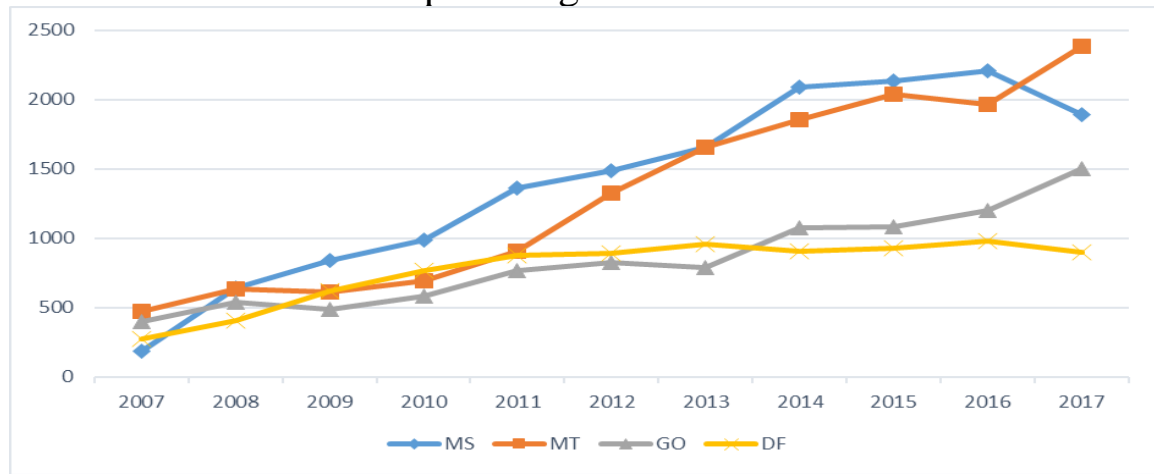

Fonte: Elaborado pelos autores com base nos dados do Censo Escolar da Educação Básica Microdados (2007 a 2017), disponibilizados pelo INEP/MEC 
Foram observados períodos específicos de decréscimo no número de matrículas em todos os estados. Mato Grosso do Sul foi o estado que, em certa medida, apresentou maior estabilidade durante os anos investigados, com um período de queda entre 2016 e 2017. O estado de Mato Grosso também apresentou algumas instabilidades. Inicialmente, houve um aumento de matrículas entre os anos de 2007 e 2008, seguida por uma pequena queda. $\mathrm{O}$ crescimento no número de matrículas foi recuperado e houve uma nova queda em 2015. A partir de 2016 o número de matrículas voltou a crescer.

A evolução de matrículas no estado de Goiás se equiparou ao de Mato Grosso e do Distrito Federal (duas quedas durante os últimos 10 anos): entre os anos de 2008-2009 e 2012-2013 em Goiás e entre os anos de 2013-2014 e 2016-2017 no Distrito Federal.

Apesar das oscilações observadas, no período investigado (2007-2017), como evidenciado na Tabela 1, foi registrada taxa de crescimento geométrico médio ao ano de: 26\% em Mato Grosso do Sul; 17,6\% em Mato Grosso; 14,2\% em Goiás; 12,7\% no Distrito Federal. Destaca-se que, no ano de 2017, o estado de Mato Grosso foi o que apresentou o maior número de matrículas, seguido por Mato Grosso do Sul, Goiás e Distrito Federal.

Tabela 01 - Número de matrículas de alunos PAEE em classes regulares nas escolas do campo da região Centro-Oeste e taxa de crescimento geométrico médio

\begin{tabular}{|c|c|c|c|c|c|c|c|c|c|c|c|c|}
\hline \multirow[b]{2}{*}{ Estado } & \multicolumn{11}{|c|}{ Número de matrículas por ano } & \multirow[t]{2}{*}{$\operatorname{Tcgm}^{1}$} \\
\hline & 2007 & 2008 & 2009 & 2010 & 2011 & 2012 & 2013 & 2014 & 2015 & 2016 & 2017 & \\
\hline$M S$ & 188 & 645 & 840 & 987 & 1366 & 1485 & 1658 & 2088 & 2137 & 2208 & 1894 & $26 \%$ \\
\hline$M T$ & 471 & 636 & 616 & 695 & 906 & 1323 & 1658 & 1853 & 2037 & 1968 & 2385 & $17,6 \%$ \\
\hline$G O$ & 397 & 539 & 485 & 581 & 767 & 826 & 792 & 1079 & 1081 & 1203 & 1500 & $14,2 \%$ \\
\hline$D F$ & 273 & 406 & 622 & 764 & 881 & 894 & 956 & 904 & 931 & 978 & 901 & $12,7 \%$ \\
\hline
\end{tabular}

${ }^{1}$ Taxa de crescimento geométrico médio.

Fonte: Elaborado pelos autores com base nos dados do Censo Escolar da Educação Básica Microdados (2007 a 2017), disponibilizados pelo INEP/MEC

b) Número de alunos PAEE matriculados em escolas do campo por dependência administrativa

No que diz respeito à dependência administrativa, os resultados apontam que há a presença de alunos PAEE matriculados em escolas do campo públicas (federais, estaduais e municipais) e privadas, como mostra a Tabela 2. Observa-se, inicialmente, 
que o número de matrículas está localizado predominantemente na rede pública, nas esferas municipais e estaduais de ensino, assim como também evidenciado por resultados de estudos que investigaram tais índices em proporção nacional (MELETTI; RIBEIRO, 2014).

É importante destacar que o número de matrículas na esfera federal, embora pequeno, apresentou aumento significativo no ano de 2015, e o índice manteve-se estável até 2017. Por sua vez, entre as escolas privadas, o número de matrículas teve um aumento significativo nos anos de 2008 e 2014, seguido de queda e, no final do período, apresentou o mesmo índice em relação ao ano inicial (22 matrículas).

Tabela 02 - Matrículas de alunos PAEE em escolas do campo na região Centro-Oeste por dependência administrativa

\begin{tabular}{lccccccccccc}
\hline & \multicolumn{10}{c}{ Número de matrículas } \\
\cline { 2 - 12 } $\begin{array}{l}\text { Dependência } \\
\text { administrativa }\end{array}$ & 2007 & 2008 & 2009 & 2010 & 2011 & 2012 & 2013 & 2014 & 2015 & 2016 & 2017 \\
\hline Federal & 6 & 4 & 2 & 10 & 18 & 23 & 36 & 23 & 53 & 52 & 53 \\
\hline Estadual & 465 & 1048 & 1373 & 1526 & 1829 & 2016 & 2493 & 2599 & 2714 & 3063 & 2867 \\
\hline Municipal & 836 & 1131 & 1251 & 1531 & 2079 & 2479 & 2540 & 3275 & 3434 & 3262 & 3782 \\
\hline Privada & 22 & 43 & 17 & 22 & 29 & 20 & 17 & 58 & 21 & 29 & 22
\end{tabular}

Fonte: Elaborado pelos autores com base nos dados do Censo Escolar da Educação Básica Microdados (2007 a 2017), disponibilizados pelo INEP/MEC

c) Número de matrículas de alunos PAEE em escolas do campo por etapa/modalidade de ensino

Dentre os dados, também foram levantados indicadores educacionais referentes ao número de matrículas de alunos PAEE em escolas do campo por etapa/modalidade de ensino (Tabela 3). Tais dados são de suma importância, pois a partir deles é possível acompanhar e problematizar o fluxo de matrículas de alunos PAEE, desde o início até o final da Educação Básica.

Em âmbito geral, observa-se que, entre as etapas/modalidades de ensino, a que tem maior representação numérica de matrículas é o Ensino Fundamental, seguido de Ensino Médio, EJA, Educação Infantil e Educação Profissional.

$\mathrm{Na}$ Educação Infantil, observa-se que o número de matrículas entre os anos de 2007 e 2017 tendeu a crescer. O estado de Mato Grosso do Sul apresentou algumas oscilações nos índices de matrículas, e sua maior contingência numérica foi no ano de 2016, quando 32 alunos representavam $0,72 \%$ do total na região. O estado com maior 
representatividade nessa etapa é o Mato Grosso. Com oscilações proporcionais próximas a 1\%, o estado fechou os 10 anos com um aumento de $178,35 \%$ e com maior pico proporcional no ano de 2016, quando 61 alunos representavam 1,38\% em relação aos números totais (maior proporção entre todos os estados).

Ainda na Educação Infantil, o estado de Goiás também apresentou certa representatividade com números brutos e proporcionais maiores que o estado de Mato Grosso e Distrito Federal. Durante os 10 anos analisados, o estado apresentou um crescimento no número de matrículas correspondentes a $240 \%$, com maior pico de matrículas em 2017. Também com maior índice de alunos nesse ano, o Distrito Federal alcançou 15 matrículas, representando $0,32 \%$ do total de matrículas em relação a região e com um aumento de $36,3 \%$ em relação aos últimos 10 anos levantados pelo presente estudo.

Tabela 3 - Matrículas de alunos PAEE em escolas do campo na região Centro-Oeste por etapa/modalidade de ensino

Número de matrículas

\begin{tabular}{lcccccccccccc}
\hline Etapa/modalidade & & 2007 & 2008 & 2009 & 2010 & 2011 & 2012 & 2013 & 2014 & 2015 & 2016 & 2017 \\
\hline \multirow{5}{*}{ Educação Infantil } & MS & 6 & 6 & 7 & 8 & 17 & 16 & 13 & 22 & 19 & 32 & 32 \\
& MT & 19 & 21 & 11 & 23 & 45 & 37 & 33 & 40 & 45 & 61 & 53 \\
& GO & 10 & 8 & 16 & 13 & 15 & 26 & 14 & 17 & 29 & 32 & 34 \\
& DF & 11 & 5 & 10 & 10 & 8 & 4 & 4 & 5 & 9 & 11 & 15 \\
\hline \multirow{5}{*}{ Funsino } & MS & 176 & 410 & 465 & 606 & 816 & 881 & 979 & 1205 & 1273 & 1304 & 1179 \\
& MT & 410 & 520 & 471 & 502 & 621 & 839 & 909 & 954 & 1060 & 1059 & 1241 \\
& GO & 381 & 491 & 454 & 495 & 601 & 619 & 607 & 716 & 745 & 893 & 979 \\
Ensino Médio & DF & 253 & 394 & 369 & 401 & 461 & 473 & 470 & 463 & 478 & 485 & 487 \\
\hline \multirow{5}{*}{ Educação } & MS & 0 & 5 & 12 & 21 & 24 & 24 & 34 & 54 & 77 & 91 & 74 \\
Profissional & MT & 11 & 8 & 16 & 7 & 5 & 7 & 56 & 93 & 120 & 165 & 231 \\
& GO & 9 & 35 & 19 & 20 & 27 & 29 & 26 & 39 & 42 & 56 & 63 \\
& DF & 6 & 2 & 9 & 9 & 17 & 15 & 16 & 33 & 38 & 47 & 48 \\
\hline \multirow{5}{*}{ EJA } & MS & 0 & 0 & 0 & 1 & 1 & 1 & 0 & 0 & 2 & 2 & 3 \\
& MT & 1 & 0 & 0 & 1 & 3 & 2 & 3 & 1 & 0 & 1 & 6 \\
& GO & 3 & 2 & 2 & 5 & 4 & 6 & 9 & 3 & 27 & 21 & 4 \\
& DF & 1 & 0 & 0 & 1 & 2 & 2 & 3 & 1 & 4 & 3 & 3 \\
\hline Fonte: & MS & 6 & 21 & 32 & 20 & 29 & 26 & 34 & 36 & 34 & 30 & 46 \\
& MT & 30 & 44 & 61 & 46 & 24 & 20 & 88 & 81 & 94 & 80 & 92 \\
& GO & 3 & 0 & 6 & 12 & 10 & 11 & 5 & 6 & 5 & 11 & 12 \\
& DF & 2 & 5 & 6 & 0 & 2 & 9 & 10 & 6 & 17 & 28 & 21 \\
\hline
\end{tabular}

Fonte: elaborado pelos autores com base nos dados do Censo Escolar da Educação Básica Microdados (2007 a 2017), disponibilizados pelo INEP/MEC 
O Ensino Fundamental foi a etapa de ensino que alcançou os maiores índices com aumentos entre 92\% (no Distrito Federal) e 570\% (em Mato Grosso).

Um dado importante evidenciado pelos resultados é o número baixo de matrículas no Ensino Médio em comparação ao Ensino Fundamental, como também observado em nível nacional (MELETTI; RIBEIRO, 2014). Sobre este aspecto, a pesquisa de Nozu (2017) aponta que o fluxo de matrículas de alunos campesinos na Educação Básica muitas vezes é interrompido, considerando que muitas escolas do campo oferecem apenas a etapa do Ensino Fundamental.

Ainda assim, observou-se o crescimento expressivo do número de alunos PAEE no Ensino Médio, em todos os estados, quando comparado com o Ensino Fundamental, apresentando aumentos que aproximam-se desde sete (no Distrito Federal) a até 20 vezes (em Mato Grosso) a mais que o número inicial.

O Ensino Médio no estado de Mato Grosso do Sul até o ano de 2007 não possuía matrículas, entretanto, a partir de 2008 o índice de matrículas aumentou de forma constante. Mato Grosso, como apontado anteriormente, foi o estado que apresentou o maior crescimento. De modo geral, o número de matrículas dos alunos PAEE no Ensino Médio nas escolas do campo é significativamente menor quando comparado ao índice de matrículas no Ensino Fundamental. Esse dado pode ser observado ao longo dos 10 anos investigados, apesar do número de matrículas no Ensino Médio apresentar aumento, ainda que inconstante, em todos os estados e no Distrito Federal.

A Educação Profissional foi a modalidade de ensino na qual observou-se, nos últimos 10 anos, menor número de matrículas dos alunos PAEE, em todos os estados da região Centro-Oeste, assim como no Distrito Federal.

A EJA é uma modalidade que tem como fim dar possibilidade a alunos que não tiveram acesso ou continuidade de seus estudos (Ensino Fundamental e Médio) em idade escolar própria. Os índices de matrículas do PAEE nessa modalidade de ensino, na região Centro-Oeste, tiveram oscilações no decorrer do período investigado. Apesar disso, considerando a diferença entre os números observados no ano inicial e final, houve um aumento significativo de matrículas. Gonçalves (2014), ao investigar experiências no âmbito do Programa Nacional de Educação na Reforma Agrária (PRONERA), conclui que a EJA em escolas de assentamentos se desenvolve em condições de precariedade, não ofertando, muitas vezes AEE aos jovens e adultos PAEE. 
d) Número de matrículas de alunos PAEE em escolas do campo por necessidade específica

Foram levantados dados de matrículas de alunos PAEE nas escolas do campo da região Centro-Oeste, de acordo com sua especificidade. Na Tabela 4, observa-se que as escolas do campo localizadas na região Centro-Oeste registraram matrículas de alunos com todos os tipos de deficiência: intelectual, física, sensorial (incluindo a surdocegueira) e múltipla.

A categoria deficiência intelectual foi a que alcançou maior índice de matrículas. Este fato não somente ocorre nessa região, como também no âmbito nacional (CAIADO; MELETTI; 2011; MELETTI; BUENO, 2011). Sobre este ponto, Nozu (2017) problematiza o perigo de muitas escolas do campo estarem produzindo suspeitas de deficiência intelectual decorrentes de diferenças socioculturais dos estudantes que vivem e produzem sua existência no meio rural.

Tabela 4 - Número de matrículas de alunos com deficiência nas escolas do campo da região Centro-Oeste

\begin{tabular}{|c|c|c|c|c|c|c|c|c|c|c|c|}
\hline \multirow{2}{*}{$\begin{array}{c}\text { Tipo de } \\
\text { deficiência }\end{array}$} & \multicolumn{11}{|c|}{ Número de matrículas } \\
\hline & 2007 & 2008 & 2009 & 2010 & 2011 & 2012 & 2013 & 2014 & 2015 & 2016 & 2017 \\
\hline $\begin{array}{l}\text { Deficiência } \\
\text { visual }\end{array}$ & 212 & 279 & 284 & 292 & 338 & 372 & 440 & 480 & 454 & 463 & 496 \\
\hline $\begin{array}{l}\text { Deficiência } \\
\text { Auditiva/surdez }\end{array}$ & 152 & 222 & 305 & 322 & 350 & 354 & 327 & 356 & 360 & 301 & 322 \\
\hline Surdocegueira & 0 & 3 & 1 & 3 & 3 & 3 & 2 & 2 & 6 & 4 & 1 \\
\hline $\begin{array}{l}\text { Deficiência } \\
\text { Física }\end{array}$ & 127 & 395 & 245 & 336 & 420 & 460 & 560 & 648 & 686 & 708 & 754 \\
\hline $\begin{array}{l}\text { Deficiência } \\
\text { Intelectual }\end{array}$ & 564 & 701 & 1636 & 2032 & 2696 & 3259 & 3751 & 4494 & 4769 & 4958 & 5172 \\
\hline $\begin{array}{l}\text { Deficiência } \\
\text { Múltipla }\end{array}$ & 56 & 116 & 157 & 140 & 195 & 215 & 256 & 317 & 332 & 392 & 425 \\
\hline
\end{tabular}

Fonte: Elaborado pelos autores com base nos dados do Censo Escolar da Educação Básica Microdados (2007 a 2017), disponibilizados pelo INEP/MEC

Além dos dados sobre matrículas de alunos com deficiência, também foi possível coletar os dados de alunos com Transtorno do Espectro Autista (TEA). Na categoria em questão, é preciso esclarecer que as denominações sofreram modificações ao longo dos 10 anos investigados. Em virtude de tais mudanças, foram contabilizados na categoria TEA os seguintes diagnósticos: Transtorno Global do Desenvolvimento, Síndrome de Asperger, Síndrome de Rett, Transtorno Degenerativo da Infância e Transtornos invasivos do desenvolvimento. Conforme pode ser observado na Figura 2, 
todas as unidades federativas da região Centro-Oeste apresentaram muitas oscilações no que diz respeito à matrícula do aluno com TEA.

Em todos os estados e no Distrito Federal, o ano de 2008 registrou um pico no número de matrículas de alunos com TEA, seguido por queda significativa no ano seguinte. Os índices observados no ano em questão não parecem refletir a realidade, já que nos anos subsequentes os números não se mantêm. É possível levantar a hipótese de que, em 2008, os instrumentos e/ou procedimentos utilizados para identificação do aluno tenham sido substituídos, pois dificilmente haveria um índice de evasão tão elevado em todas as escolas do campo da região Centro-Oeste: queda de 201 matrículas em Mato Grosso do Sul, 155 em Mato Grosso, 126 em Goiás e 56 no Distrito Federal.

Figura 2 - Número de matrículas de alunos com Transtorno do Espectro Autista em escolas do campo na região Centro-Oeste

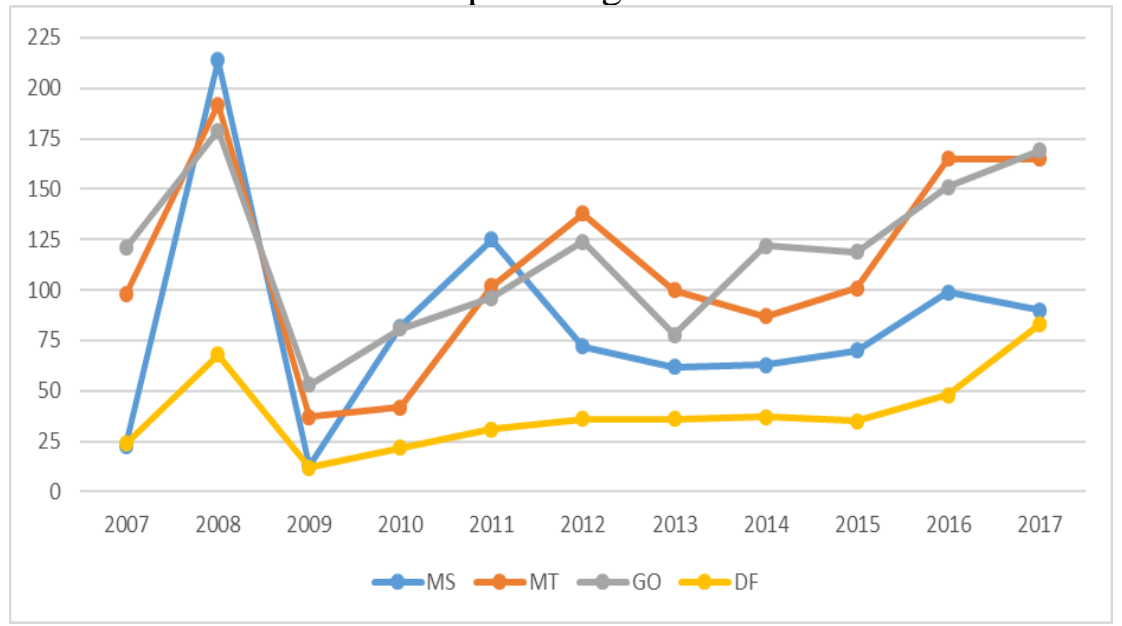

Fonte: Elaborado pelos autores com base nos dados do Censo Escolar da Educação Básica Microdados (2007 a 2017), disponibilizados pelo INEP/MEC

Por fim, o presente estudo também coletou dados acerca do número de alunos em escolas do campo da região Centro-Oeste identificados com altas habilidades/superdotação. De acordo com a Figura 3, é possível observar o número reduzido de alunos com altas habilidades/superdotação nas escolas do campo em todos os estados da região e também no Distrito Federal.

Em 2007 esse alunado representava 0,43\% do número total de matrículas na região (0,072\% em Mato Grosso do Sul; 0,361\% em Mato Grosso). No ano de 2017, estes alunos passaram a representar $1,5 \%$ do número total de matrículas $(0,37 \%$ em Mato Grosso do Sul; 0,74\% em Mato Grosso; 0,19\% em Goiás; e 0,25\% no Distrito Federal). É importante destacar que, no estado de Mato Grosso houve aumento 
significativo de matrículas de alunos com altas habilidades/superdotação nos anos de 2016 e 2017. Possivelmente tal aumento se deve ao aprimoramento dos processos de identificação do referido alunado no estado. Também merece destaque a oscilação do número de matrículas dos alunos com altas habilidades/superdotação em Mato Grosso do Sul, especialmente entre os anos de 2013 e 2017. No período indicado, as quedas e elevações nos índices podem significar tanto a evasão de tais alunos, como refletir a dificuldade das unidades escolares em identificar o público em questão.

Figura 3 - Número de matrículas de alunos com altas habilidades/superdotação em escolas do campo na região Centro-Oeste

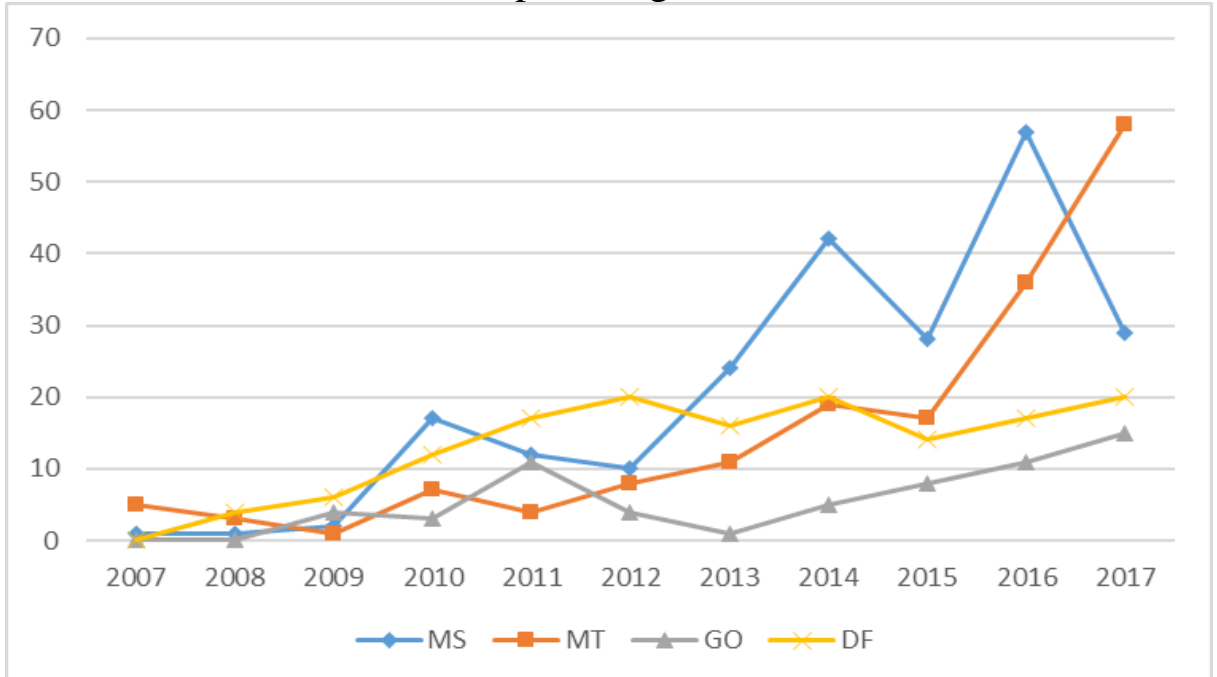

Fonte: Elaborado pelos autores com base nos dados do Censo Escolar da Educação Básica Microdados (2007 a 2017), disponibilizados pelo INEP/MEC

\section{Considerações finais}

Os resultados indicaram que os alunos PAEE estão presentes em escolas do campo da região Centro-Oeste e que o número de matrículas cresceu nos últimos 10 anos, o que pode ilustrar os efeitos, em termos de acesso, da Política Nacional de Educação Especial na Perspectiva da Educação Inclusiva.

Entretanto, a simples presença do aluno PAEE não significa que as necessidades específicas apresentadas por esse público estão sendo atendidas. Para além do direito de matrícula, é preciso investigar o alcance de aspectos relacionados à permanência e ao desempenho/sucesso acadêmico dos estudantes PAEE nas escolas do campo.

No que diz respeito aos indicadores por etapa/modalidade de ensino, observouse que, na região Centro-Oeste, as matrículas de alunos PAEE nas escolas do campo se 
concentraram, nos últimos 10 anos, no Ensino Fundamental. Em vista disso, os achados parecem indicar que: a) grande parte dos alunos é identificada como PAEE apenas no Ensino Fundamental; b) há ruptura no fluxo de matrículas desse alunado do Ensino Fundamental para o Ensino Médio, o que denota alto índice de evasão escolar; c) uma pequena parcela dos alunos PAEE que conclui o Ensino Fundamental se matricula na Educação Profissional; d) na EJA, há alunos PAEE que não concluíram o Ensino Fundamental e/ou Médio.

Quanto às necessidades específicas, nos anos investigados, a deficiência intelectual é a categoria com maior índice de matrículas na região Centro-Oeste. Embora tal resultado seja observado nacionalmente nos diferentes sistemas de ensino, é preciso refletir se, nas escolas do campo, a incidência observada corresponde à realidade. Em outras palavras, é possível que algumas especificidades dos modos de vida no campo sejam interpretadas, sem a devida atenção às diferenças socioculturais, pela equipe escolar como características da deficiência intelectual.

Também merece destaque as oscilações nos índices de matrículas dos alunos PAEE, no que diz respeito às categorias investigadas (deficiência intelectual, deficiência física, deficiências sensoriais, TEA e altas habilidades/superdotação). Tais variações podem sinalizar a insuficiência e/ou a imprecisão nos instrumentos e/ou procedimentos utilizados para identificação das necessidades específicas apresentadas por tais alunos.

Assim, diante do cenário exposto, inúmeros desafios emergem para o processo de escolarização de estudantes PAEE em escolas do campo, que se movimentam desde a ausência/precariedade do transporte escolar rural, a distância que os campesinos têm de percorrer para estudar, o fechamento de escolas do campo, a oferta de apenas algumas etapas da Educação Básica pelas escolas do campo, passando pela questão das condições de acessibilidade arquitetônica e material, pelo Projeto Político-Pedagógico das instituições educacionais e pela formação e o regime de trabalho dos docentes (generalistas e especialistas), até chegar nas estratégias de inclusão desses sujeitos nas classes comuns, bem como na disponibilização de serviços especializados para o atendimento de suas necessidades educacionais específicas. Tratam-se de desafios que emergem da imbricação entre a Educação Especial e a Educação do Campo e que podem requerer investigações empíricas macro, meso e microcontextuais para o aprofundamento da análise da inclusão de alunos PAEE oriundos de assentamentos, acampamentos, fazendas/sítios, florestas, ilhas, terras indígenas e quilombolas, dentre outros locais de produção da existência dos povos do campo. 


\section{REFERÊNCIAS}

BRASIL. Política nacional de educação especial na perspectiva da educação inclusiva. Brasília, DF: MEC/SEESP, 2008a.

BRASIL. Resolução n. 2, de 28 de abril de 2006. Estabelece diretrizes

complementares, normas e princípios para o desenvolvimento de políticas públicas de atendimento da Educação Básica do Campo. Brasília, DF: MEC/CNE/CEB, 2008b.

CAIADO, Katia Regina Moreno.; MELETTI, Silvia Márcia Ferreira. Educação especial na educação do campo: 20 anos de silêncio no GT 15. Revista Brasileira de Educação Especial, Marília, v. 17, p. 93-104, maio/ago., 2011.

GONÇALVES, Taísa Grasiela Gomes Liduenha. Alunos com deficiência na educação de jovens e adultos em assentamentos paulistas: experiências do PRONERA. 2014. 199 f. Tese (Doutorado em Educação Especial) - Centro de Educação e Ciências Humanas, Universidade Federal de São Carlos (UFSCar), São Carlos, 2014.

INEP. Microdados. Disponível em: http://portal.inep.gov.br/microdados. Acesso em: 28 ago. 2018.

JESUS, Denise Meyrelles de.; ANJOS, Christiano Félix dos. Tecendo interfaces entre a educação especial e a educação do campo: o cenário do Espírito Santo. In: XVI ENDIPE - Encontro Nacional de Didática e Práticas de Ensino, 2012, Campinas. Anais... Campinas: UNICAMP, 2012, p. 1820-1829.

MAINARDES, Jefferson.; MARCONDES, Maria Inês. Entrevista com Stephen J. Ball: um diálogo sobre justiça social, pesquisa e política educacional. Educ. Soc., Campinas, v. 30, n. 106, p. 303-318, jan./abr., 2009.

MARCONI, Marina de Andrade.; LAKATOS, Eva Maria. Fundamentos de metodologia científica. 6 ed. São Paulo: Atlas, 2007.

MELETTI, Silvia Márcia Ferreira.; BUENO, José Geraldo Silveira. O impacto das políticas públicas de escolarização de alunos com deficiência: uma análise dos indicadores sociais no Brasil. Linhas Críticas, Brasília, v. 17, n. 33, p. 367-383, maio/ago. 2011.

MELETTI, Silvia Márcia Ferreira; RIBEIRO, Karen. Indicadores educacionais sobre a Educação Especial no Brasil. Caderno Cedes, Campinas, v. 34, n. 93, p. 175-189, 2014.

NOZU, Washington Cesar Shoiti. Educação especial e educação do campo: entre fronteiras marginais e fronteiras culturais. 2017. 235 f. Tese (Doutorado em Educação) - Faculdade de Educação, Universidade Federal da Grande Dourados (UFGD),

Dourados, 2017.

SOARES, Scheilla. Sujeitos do campo considerados deficientes: da invisibilidade ao pertencimento. 2011. 197f. Dissertação (Mestrado em Educação) - Centro de Ciências da Educação, Universidade Federal de Santa Catarina (UFSC), Florianópolis, 2011. 


\section{Como referenciar este artigo}

NOZU, Washington Cesar Shoiti.; SILVA, Aline Maira da.; SANTOS, Bruno Carvalho dos. Alunos público-alvo da educação especial nas escolas do campo da região centrooeste: análise de indicadores de matrículas. Revista on line de Política e Gestão

Educacional, Araraquara, v. 22, n. esp. 2, p. 920-934, dez., 2018. E-ISSN:1519-9029. DOI: 10.22633/rpge.unesp.v22.nesp2.dez.2018.11920

Submetido em: $31 / 10 / 2018$

Aprovado em: 25/11/2018 